Herschler, M. A. and Fechheimer, N. A. (1967). The role of sex chromosome chimerism in altering sexual development of mammals. Cytogenetics, 6, 204-212.

Hinman, F. (1935). The Principles and Practice of Urology. Saunders, Philadelphia and London.

Hirschhorn, K., Decker, W. H., and Cooper, H. L. (1960). Human intersex with chromosome mosaicism of type XY/XO; report of case. New England fournal of Medicine, 263, 1044-1048.

Hungerford, D. A., Donnelly, A. J., Nowell, P. C., and Beck, S. (1959). The chromosome constitution of a human phenotypic intersex. American fournal of Human Genetics, 11, 215-236.

McFeely, R. A., Hare, W. C. D., and Biggers, J. D. (1967). Chromosome studies in 14 cases of intersex in domestic mammals. Cytogenetics, 6, 242-253.

McKusick, V. (1968). Mendelian Inheritance in Man, 2nd ed., p. 287. Johns Hopkins Press, Baltimore.

Mentz, D. (1968). Hermaphroditism, sex chromosomal mosaicism and germ cell selection in allophenic mice. B. 8th Biennial Symposium on Animal Reproduction. Fournal of Animal Science, 27, 51-60.

Overzier, C. (1964). Ein XX/XY Hermaphrodit mit einen intratublaren $\mathrm{Ei}$ und einen Gonadoblastom. (Gonocytom III). Klinische Wochenschrift, 42, 1052-1060.

Park, I.-J., Jones, H. W., Jr., and Bias, W. B. (1970). True hermaphroditism with $46, \mathrm{XX} / 46, \mathrm{XY}$ chromosome complement. Obstetrics and Gynecology, 36, 377-387.

Rosenberg, H. S., Clayton, G. W., and Hsu, T. C. (1963). Familial true hermaphroditism. Fournal of Clinical Endocrinology and Metabolism, 23, 203-206.

Russell, A. (1954). Intersexuality and the adrenogenital syndrome. In Recent Advances in Paediatrics, ed. by D. M. T. Gairdner. Churchill, London.

\section{Two Cases of Trisomy D Associated with Adrenal Tumours*}

It is becoming increasingly clear that congenital abnormalities due to chromosomal aberrations may be associated with a high incidence of neoplastic disease (Miller, 1966). In patients with Down's syndrome, the prevalence of leukaemia is increased 20-fold compared with the general population (Wald et al, 1961) and recent reports indicate that other autosomal aberrations also may have a propensity for developing neoplastic disease (Schade, Schoeller, and Schultze, 1962; Zuelzer, Thompson, and Mastrangelo, 1968; Geiser and Schindler, 1969).

The present report describes two cases of trisomy $\mathrm{D}$ associated with adrenal tumours.

\section{Case Reports}

Case 1. The youngest of 6 sibs, this boy was born on 2 May 1965 to unrelated healthy parents aged 38 (mother) and 52 years (father). Birthweight was $2950 \mathrm{~g}$; delivery was normal. There was no radiation exposure, viral

\footnotetext{
Received 7 June 1971.

* Requests for reprints to N.C.N., Human Genetics Unit, Department of Medical Statistics, Institute of Clinical Science, Grosvenor Road, Belfast BT 12 6BJ, Northern Ireland.
}

infection during pregnancy, or previous fetal loss. The remaining sibs ( 3 sisters and 2 brothers) were normal.

Multiple abnormalities were present at birth. The head was small with several mid-line scalp defects. The face was moon-shaped with bilateral microphthalmia, corneal opacities, low-set abnormal ears, a left accessory auricle, a severe bilateral hare lip, and a wide cleft involving both hard and soft palate. There was an extra digit on the right hand and on the left foot. Fingers were tightly flexed and the elbows showed a flexion deformity. Testes were small and the penis showed a mild degree of hypospadias.

Skeletal radiology showed no abnormality other than a thin cranial vault. Chromosome analysis was done on preparations of peripheral blood. Of 30 metaphases studied, all but 2 cells, which had a normal diploid number, had 47 chromosomes with the additional chromosome in the D group (47,XY,D+). The chromosomes of both parents were normal.

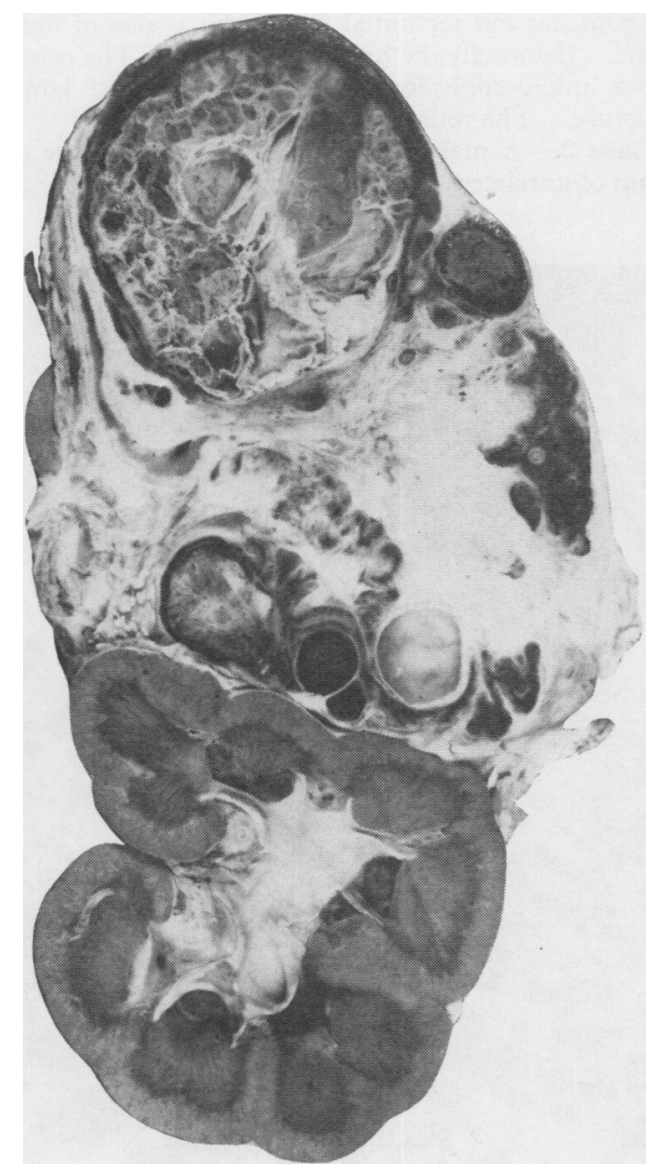

Fig. 1. Gross appearance of the adrenal tumour in case 1 showing the cystic and lobular nature. 
The infant died on the 15th day of life. At necropsy, the heart was slightly enlarged with a $2-\mathrm{cm}$ diameter atrial septal defect. The lungs were congested and oedematous. The left adrenal gland was replaced by a large tumour measuring $4 \times 3 \times 3 \mathrm{~cm}$ (Fig. 1) which was partially cystic and divided into lobules by septa. The tumour microscopically was composed of small round cells arranged in cords and acini in a pattern resembling definitive adrenal cortex (Fig. 2). Within the fibrous tissue capsule of the tumour, there were isolated irregular nodules of cells and in a few sections, these were also seen in the surrounding fat. In several areas, there were collections of large eosinophilic cells with bizarre nuclei, resembling cytomegalic cells frequently found in the fetal adrenal cortex (Fig. 3). The tumour also showed haemopoietic foci, haemorrhage, necrosis, and haemosiderin deposition. There was no tumour within either blood vessels or lymphatics.

The cortex and medulla of the thymus which was atrophied, were indistinguishable and only a few thymocytes were present. A spleniculus was associated with the pancreas but separated from it by a zone of fibrous tissue. Externally the brain was normal. The cerebral cortex microscopically had a well-developed laminar structure. The retina showed no abnormality.

Case 2. A male born 24 April 1968, was the only infant of unrelated, healthy parents aged 24 (mother) and

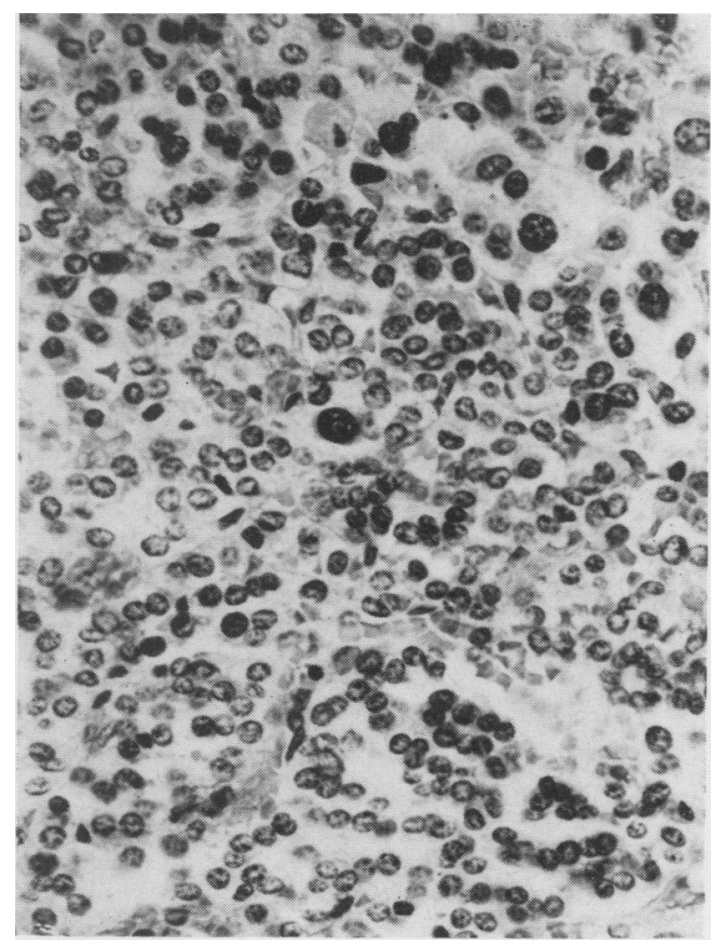

Fig. 2. Case 1. Irregular cords of uniform round cells interspersed with cells showing cytomegalic change $(\mathrm{H} \& \mathrm{E}, \times 260)$.
25 years (father). The pregnancy was uneventful and terminated spontaneously at 34 weeks gestation. Birthweight was $1955 \mathrm{~g}$. There was no previous fetal loss, history of maternal exposure to radiation, or viral infection during the pregnancy.

He was admitted to hospital on the day of delivery because of multiple abnormalities. The skull was small (circumference $32 \mathrm{~cm}$ ). The facies was abnormal with a receding forehead, bulbous nose, depressed nasal bridge, bilateral microphthalmia, low-set abnormal ears, micrognathia, and a wide cleft involving both hard and soft palate. The fingers were firmly flexed and an extra digit was present on the hands and feet. There were several small capillary haemangiomata on the nape of the neck. An omphalocoele, measuring $4 \times 5 \times 5 \mathrm{~cm}$, contained several loops of the small bowel. The penis and scrotum were small; both testes were normal.

Dermatoglyphic studies showed a bilateral simian crease and distally placed axial triradii $\left(t^{\prime \prime}\right)$. An arch fibular S pattern was seen in the hallucal areas. Chromosome analysis was done on preparations of peripheral blood. Each of the 10 metaphases examined had a total of 47 chromosomes with the extra chromosome belonging to group $\mathrm{D}(47, \mathrm{XY}, \mathrm{D}+)$. The chromosomes of both parents were normal.

The baby died on the 4th day of life. At necropsy the main abnormalities were confined to the brain and

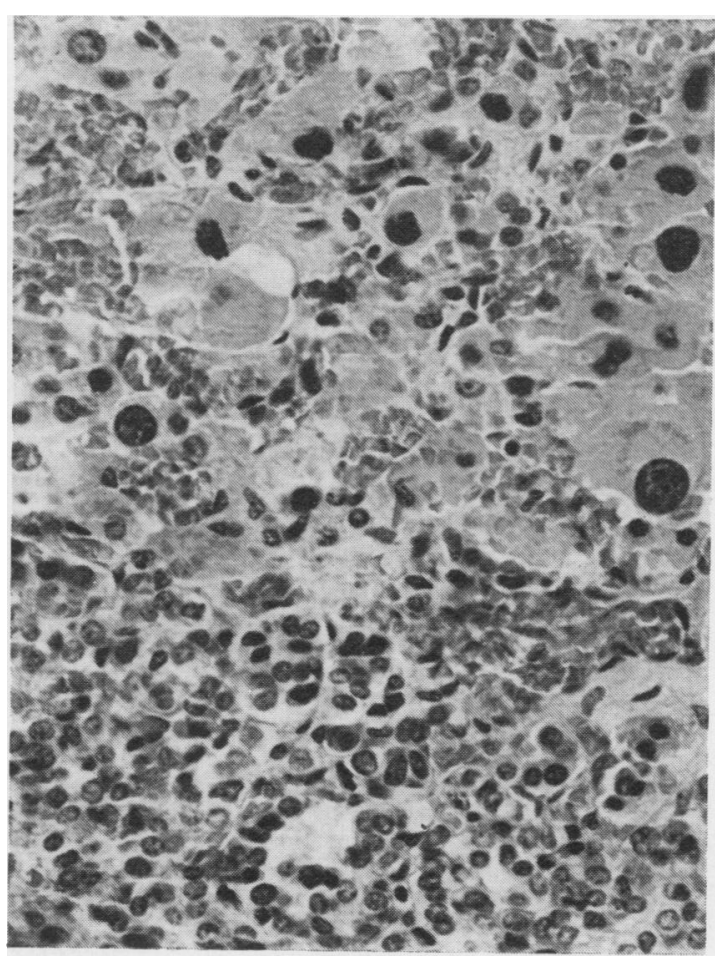

Fig. 3. Case 1. Cells showing cytomegalic change $(\mathrm{H} \& \mathrm{E}, \times 270)$. 


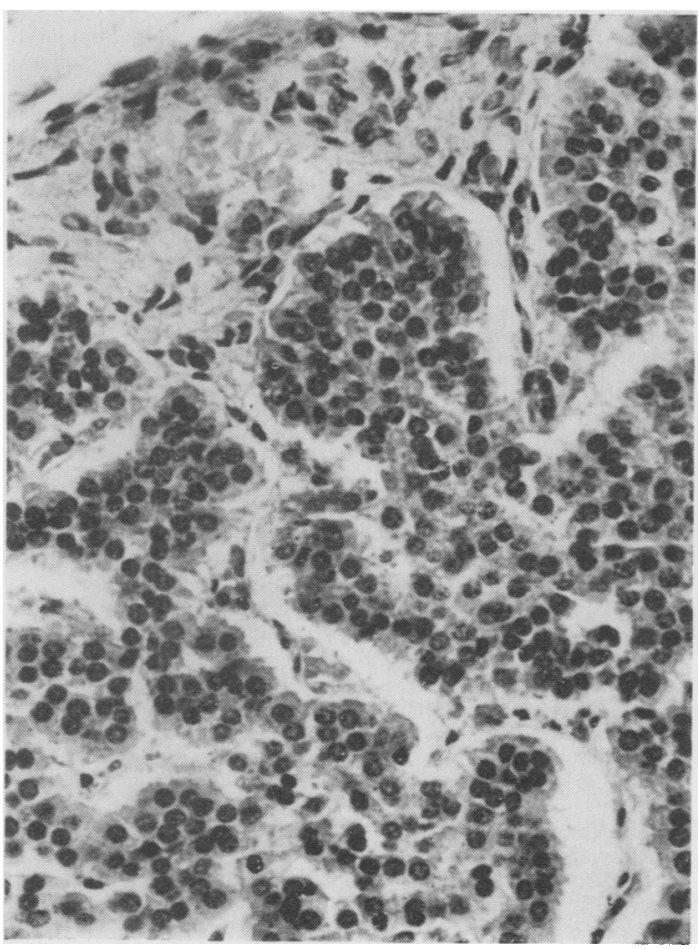

Fig. 4. Case 2. Adrenal cortex showing cortical hyperplasia (H \& E, $\times 270$ ).

adrenals. Several abnormalities were noted on external examination of the brain. The frontal lobes, although fore-shortened, were not fused. The olfactory bulbs and tracts were absent. The olfactory sulci were easily identified on the inferior surface of the frontal lobes; the left sulcus was more medial than the right. The medial and lateral striae also were absent. The anterior limb of the fornix was deficient and the genu, anterior part of the corpus callosum, and septum pellicudum were absent. The medial longitudinal striae were not identified. The fimbria commenced in the hippocampus and the alveus and continued into the fornix. There was no abnormality in the corpora mamillaria, the basal ganglia, thalamus, mid-brain, brain stem, cerebellum, or spinal cord. The anterior clinoid processes and the pituitary diaphragm were absent.

There was a focal spleniculosis throughout the pancreas and a well-defined spleniculum fused with the surrounding pancreatic tissue. The adrenal glands showed hyperplasia of the definitive cortex (Fig. 4). In one adrenal gland there was a microscopic neuroblastoma in the medulla (Fig. 5).

\section{Discussion}

The role of chromosome changes in carcinogenesis has long been the subject of debate and

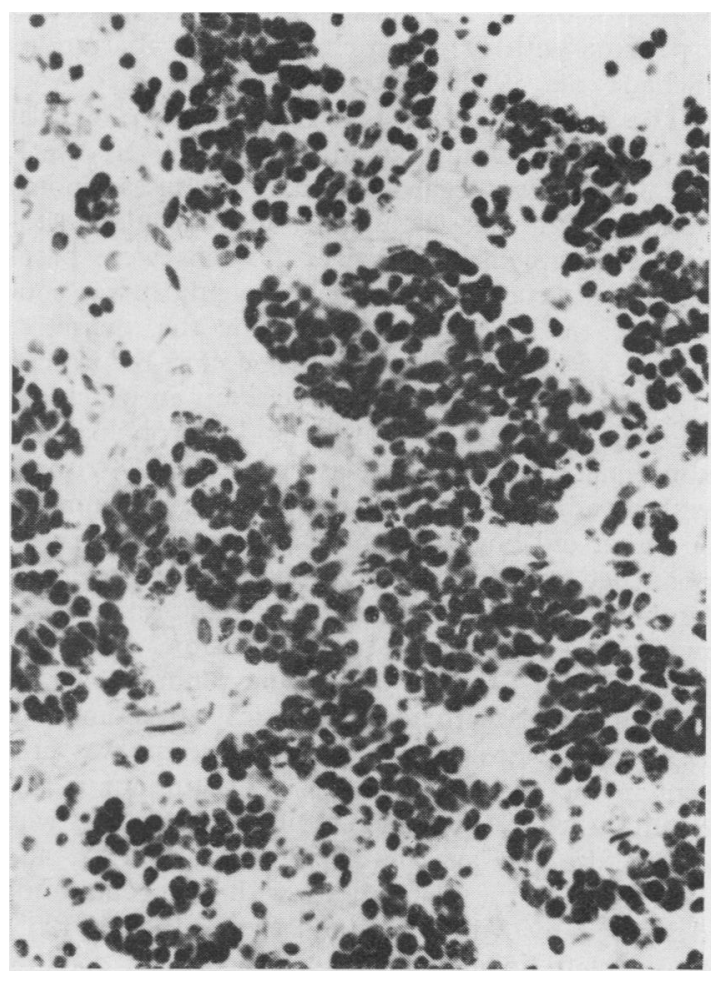

FIG. 5. Photomicrograph of tumour in case 2 showing groups of neuroblasts in the adrenal medulla $(H \& E, \times 260)$.

much investigation. In the light of recent cytogenetic findings on invasive tumours and preinvasive lesions, it now seems apparent that chromosome changes are intimately concerned with development of the majority of human tumours. However, whether these changes are the direct causation of the malignant state or the consequence of the disease is still unresolved. One approach to this problem has been the investigation of individuals with congenital abnormalities due to an underlying chromosome aberration and their subsequent risk of developing cancer or leukaemia (Harnden, 1970).

Individuals with congenital abnormalities due to aneuploidy have a substantial risk of leukaemia (Wald et al, 1961; Miller, 1966) but the occurrence of tumours in such patients has been less well documented. Patients with Down's syndrome have a tendency to develop tumours of the central nervous system (Miller, 1966) and patients with XY gonadal dysgenesis may show malignant change in the gonadal streaks (Sternberg, Barclay, and Kloepfer, 1968). Other autosomal aberrations might also have some propensity for developing 
neoplastic disease. Leukaemia has been reported in 2 patients with D group chromosomal aberrations (Schade et al, 1962; Zuelzer et al, 1968).

The present cases of D-trisomy each had, at necropsy, a tumour of an adrenal gland. In case 1, the tumour was regarded as a probable carcinoma because of its size, cellularity, and irregular histological arrangement, because the cells were basophilic and arranged in cords and acini, it was considered to have originated from the definitive cortex. Marin-Padilla, Hoefnagel, and Benirschke (1964) described 2 cases of D-trisomy in which the adrenal glands were enlarged and morphologically abnormal. However, the association of D-trisomy with an adrenal cortical carcinoma is most unusual. A 5-year-old boy with an anaplastic adrenal carcinoma had, on chromosome analysis of the peripheral lymphocytts, an extra large sub-metacentric chromosome similar to group B (Pascasio et al, 1967). Ellwood and Pearson (1968) found normal karyotypes in 2 girls with adrenal cortical carcinomas.

In case 2 , a microscopic neuroblastoma was present in the adrenal medulla. This tumour is frequently seen as an incidental finding in infants who die before the age of 3 months (Beckwith and Perrin, 1963). The child with neuroblastoma described by Mittelbach and Szekely (1934/1935) had a cleft lip and palate, microcephaly, cerebral atrophy, absence of the corpus callosum, widely patent ductus arteriosus, and patent foramen ovale -features suggestive of D-trisomy. Cytogenetic findings in children with neuroblastoma have been variable; Nichols (1968) did not observe any abnormality but recently Wakonig-Vaartaja et al (1971) who studied 21 children with neuroblastoma noted an increased number of abnormal metaphases in pretreatment samples of peripheral blood and bone marrow.

\section{Summary}

Two unrelated infants with D-trisomy and adrenal tumours are reported. The first patient who died aged 15 days had a large adrenal cortical carcinoma; the second who died aged 5 days had a microscopic neuroblastoma. The relationship of chromosome changes and the development of malignant tumours is discussed.

N. C. Nevin, J. A. Dodge, and Ingrid V. Allen

Human Genetics Unit, Department of Medical Statistics, and Departments of Child Health and Pathology, The Queen's University of Belfast

\section{REFERENCES}

Beckwith, J. B. and Perrin, E. V. (1963). In situ neuroblastomas A contribution to the natural history of neural crest tumors. American fournal of Pathology, 43, 1089-1100.

Ellwood, L. C. and Pearson, H. A. (1968). Normal lymphocyte karyotypes in adrenocortical carcinoma. Lancet, 1, 302.

Geiser, C. F. and Schindler, A. M. (1969). Long survival in a male with 18-trisomy syndrome and Wilm's tumour. Pediatrics, 44, 111-116.

Harnden, D. G. (1970). Genetic Concepts and Neoplasia, p. 31. Williams and Wilkins, Baitimore.

Marin-Padilla, M., Hoefnagel, D., and Benirschke, K. (1964). Anatomic and histopathologic study of two cases of $D_{1}(13-15)$ trisomy. Cytogenetics, 3, 258-284.

Miller, R. W. (1966). Relation between cancer and congenital defects in man. New England Fournal of Medicine, 275, 87-93.

Mittelbach, M. and Szekely, P. (1934/1935). Ein Fall von Neuroblastom des Nebennierenmarkes mit mehreren Missbildungen. Frankfurt Zeitschrift fiir Pathologie, 47, 517-521.

Nichols, W. W. (1968). Cytogenetic aspects of neuroblastoma. fournal of Pediatric Surgery, 3, 143-146.

Pascasio, F. M., Jesalva, P. S., Cruz, E. P., and Alikpala, S. (1967). Extra large chromosome in adrenocortical carcinoma. Lancet, 1, 1107.

Schade, H., Schoeller, L., and Schultze, K. W. (1962). D-Trisomie (Patau-Syndrom) mit kongenitaler myeloischer Leukämie. Medizinische Welt, 2, 2690-2692.

Sternberg, W. H., Barclay, D. L., and Kloepfer, H. W. (1968). Familial XY gonadal dysgenesis. New England fournal of Medicine, 278, 695-700.

Wald, N., Borges, W. H., Li, C. C., Turner, J. H., and Harnois, M. C. (1961). Leukaemia associated with mongolism. Lancet, 1, 1228.

Wakonig-Vaartaja, T., Helson, L., Baren, A., Koss, L. G., and Murphy, M. L. (1971). Cytogenetic observations in children with neuroblastoma. Pediatrics, 47, 839-843.

Zuelzer, W. W., Thompson, R. I., and Mastrangelo, R. (1968). Evidence for a genetic factor related to leukaemogenesis and congenital anomalies: chromosomal aberrations in pedigree of an infant with partial D trisomy and leukaemia. Fournal of Pediatrics, 72, 367-376.

\section{Congenital Hypothyroidism in Association with a Ring Chromosome 18}

Previous reports of hypothyroidism in association with short arm deficiency of chromosome 18 (Bühler, Bühler, and Stalder, 1964; Uchida et al, 1965) have suggested a possible role for this chromosome in the embryogenesis of the thyroid gland. The present finding of a ring chromosome 18 in a girl with congenital hypothyroidism lends further support to this hypothesis.

\section{Case Report}

This girl presented at 10 years 9 months with a complaint of visual hallucinations of 3 weeks' duration. She had been the product of a 38-week uneventful pregnancy and normal delivery. Her birth weight was $3.18 \mathrm{~kg}$,

Received 24 March 1971. 